\title{
A Study on the After-Class Practice of Chinese Textbooks in the Period of the Republic of China-A Study of Kaiming Chinese Textbook
}

\author{
Jingya Liu, Jumei Xiao \\ Huzhou Teachers College, Zhejiang, China
}

\begin{abstract}
In the period of the Republic of China, the after-class practice of Kaiming Chinese Textbook mainly includes seven types of questions, such as practicing Chinese characters, making sentences, reading pictures, answering questions, etc. It has the following characteristics: word practice step-by-step, writing practice is practical, activity practice hand brain combination, reading pictures practice is full of interest, etc. By summing up the content and characteristics of the after-class practice, we can draw inspiration from the compilation of the modern primary school Chinese textbook after-class practice: pay attention to the specific situation of font diversification and word learning; promote the writing practice to be more practical; improve the activity practice to improve the students' brain and hands-on ability; add the related map reading exercise to improve the students' cognitive ability, etc.
\end{abstract}

Keywords: Republic of China period, Chinese teaching materials, after-class practice

\section{Introduction and Method}

Chen Danqing, a Chinese painter, said, "The Republic of China is not only about traditional culture. The good reason for the Republic of China is that the things from the West and the traditional things are just in the same situation" (Chen, 2012). In recent years, researchers' pursuit and research of Chinese textbooks in the period of the Republic of China are also growing. Whether it is art or education, the Republic of China seems to have left a very deep impression. Based on this, this paper intends to start with the Kaiming Chinese Textbook (Volumes 5 and 6) in the period of the Republic of China, study its after-class practice content, summarize its characteristics, and hope to inspire the compilation of modern Chinese textbooks.

By summarizing the type of after-class practice in Kaiming Chinese Textbook (Volumes 5 and 6) and comparing the book with the third grade Chinese book published by People's Education Edition, we get the advantages and references of the exercises after class in Kaiming Chinese Textbook.

\section{Findings and Discussion}

\section{Classification of Practice After-Class in Kaiming Chinese Textbook}

In 1932, Kaiming Chinese Textbook, which was compiled by Mr. Ye Shengtao and illustrated by Mr. Feng Zikai and used as a primary school, was published in Shanghai Kaiming Bookstore. With the emergence

Jingya Liu, M.A., College of Teacher Education, Huzhou Teachers College.

Jumei Xiao, Ph.D., associate professor, College of Teacher Education, Huzhou Teachers College. 
of textbooks, primary school teachers at that time thought that these textbooks should be compiled in order to improve students' interest in learning. In 1937, the Anti-Japanese War broke out in an all-round way, and many books in Shanghai Kaiming Bookstore were forced to stop printing including all primary school textbooks, including Kaiming Chinese Textbook. It was not until the 1980s that Mr. Ye Shengtao recalled compiling such a primary school textbook 50 years ago. In his opinion, the Chinese textbooks prepared for children should pay attention to the cultivation of their reading and writing ability, so the textbooks need to conform to the laws and procedures of Chinese training. In addition, for the primary school students who are still children, the articles in the textbooks must be children's literature, so as to attract their reading interest and develop their wisdom in all aspects. Based on this, Kaiming Chinese Textbook was compiled and printed. There are seven types of exercises in five or six volumes of Kaiming Chinese Textbook:

From the side and font practice. Start with the side-by-side, and gradually let students master different fonts. For example, in the after-school practice of Lesson 4 of Volume 5, "Our school", students are required to describe and practice Chinese characters mainly by “父” and “之”, and the font is required to be in regular script. While in Lesson 17, "National Day Speech", the font is required to be in running script.

Make sentences with word, words, and related words. Make students expand the use of words on the basis of mastering basic words. For example, in the after-class practice of Lesson 12 in Volume 5, "Carpentry", the words "still" and "sleep" are required to make sentences; in Lesson 8, "Farmer and Hare", the words "gently" and "often" are required to make sentences; in Lesson 36, "Old Man With White Beard", the words "although" and "but" are required to make sentences.

Look at the picture practice. Through the observation and expression of pictures, we can cultivate students' expression ability and stimulate students' interest in learning. For example, there are six pictures in the practice after-class in Lesson 13 of Volume 6, "Courage and Strength". Students are required to express their language according to the development of the plots in the pictures. There are two pictures in Lesson 30, "Bailing Water", and students are required to write two stories instead of them.

Answer questions. By answering questions, according to different requirements, students can be trained to solve problems. For example, in Book 5, Lesson 4, the first four questions of after class practice in "Our School" require students to talk about their school environment, teachers, and students according to the actual situation; in Lesson 27, "This is the Case", give a story of students telling jokes and ask students to answer questions according to the content of the problem.

Organization ability questions. Through discussion and thinking, students can express in an organized way to improve their organizational ability. For example, in Lesson 42, Volume 5, after-class practice of "Lunar New Year's Eve (3)", the students are required to discuss the plan of performing at the Lunar New Year's Eve, that is to say, how to prepare the setting, who is the most suitable and how to practice each one's speaking.

Write letters. By writing different types of letters, students can master basic social skills and adapt to the needs of the times. For example, in the after-class practice of Lesson 17, Volume 5, "National Day Speech", no matter to whom you write, ask the students to write an invitation letter; in Lesson 18, Volume 6, "A Letter From Shanghai", no matter to whom you write, ask the students to write a reply letter as Zhang Xinhua's cousin; in Lesson 25, "A Telegram", ask the students to send a telegram according to the content given in the question. 
Other topics, such as diary, imagination, etc. For example, after-class practice in Lesson 34, Volume 6, "In the Park", requires students to write down one or two events of the day in a diary; and Lesson 40, "Moonlit Night", requires students to imagine the dialogue between dragonflies and cicadas.

\section{Characteristics of After-Class Practice in Kaiming Chinese Textbook}

Through the analysis and comparison of these seven types of questions, we explore the four characteristics of their after-school exercises.

Word practice step-by-step. The so-called "step-by-step", that is to say, "step-by-step" in a certain order. The two types of exercises of practicing Chinese characters and making sentences in Kaiming Chinese Textbook fully reflect this feature. For practicing Chinese characters, first of all, we should start from the side of the characters and master the ability to write the characters belonging to the side of the characters by describing and writing the same side of the characters. Then, we should start from the font of the characters. Most of the fonts have two versions, namely, regular script and running script. When the students' mastery of regular script is gradually stable, they will transition to running script. In particular, for font practice, the Chinese characters that need to be practiced in the textbooks are all written by the famous painter and calligrapher Mr. Feng Zikai. Compared with the lifeless printing, the Chinese characters written by Mr. Feng Zikai may be easier for students to have a cordial feeling. When students have the ability to read and write new words, practice requires students to make sentences on this basis. From words to words, then to related words, from simple to complex, from easy to difficult. And in the process of making sentences, we should pay attention to the specific context, so that students can better understand and use words in the given context.

Writing practice is practical. Practical means adapting to the requirements of the time. Mr. Ye Shengtao pointed out in the editorial gist of Kaiming Chinese Textbook, "This book tries to accommodate all kinds of styles needed in children's literature and daily life". In his reply to the Kaiming Chinese Textbook, he said, "The practical styles of notes, letters, telegrams, advertisements, articles of association, opinions, and so on are all daily needed to be applied. The Mandarin textbook should provide some paradigms. In the Kaiming Chinese Textbook, there are not only literary styles - fairy tales, stories, poems, plays, etc., but also practical styles-letters, dialogues, notes, commentaries, etc." (Shen, 2015). By summarizing the writing questions of five or six after class exercises in Kaiming Chinese Textbook, we can see that writing invitation letters, writing reply letters, generating telegrams, writing diaries, writing scripts, and compiling dialogues are all within the scope of editing gist.

Activity practice hand brain combination. The combination of hand and brain requires students to practice in thinking and think in practice. In the five or six volumes of Kaiming Chinese Textbook, there are endless exercises about activities. For example, students are required to write a play, and then students organize to perform the content of the play. What is more, students are required to perform the fable story through role play. Since the Kaiming Chinese Textbook is a product of the Republic of China, the content of the text is arranged in consideration of the current facts, so the after-class practice has the same characteristics. For example, on a national day after the founding of the Republic of China, after-class practice requires students to organize performances to celebrate the founding of the Republic of China. It is true that activities are not only limited to performances, but also require students to observe natural phenomena. In the 10 exercises after-class in Book 6 of the Kaiming Chinese Textbook, students are required to observe the rainbow in the sky and describe the rainbow they see. Students can understand the characteristics of the rainbow by observing the 
rainbow, and improve their expression ability by describing the characteristics of the rainbow, which meets the requirements of enlightening students' thinking. The cultivation of students' practical ability in the Kaiming Chinese Textbook is also reflected in the use of reference books. For example, in Lesson 9, Volume 5 teaches students how to understand the meaning of a new word through the use of a dictionary. Accordingly, students are required to use a dictionary to complete the topic in the after-class practice.

Reading pictures practice is full of interest. As we all know, the illustrations of Kaiming Chinese Textbook are from the famous painter Feng Zikai in the period of the Republic of China. Through in-depth understanding of children and education, the painter makes a picture of interesting students show in front of the students. And its "illustrations for liberal arts include plot illustrations, portrait illustrations, illustrative illustrations, and decorative illustrations" (Yu, 2012). Mr. Ye Shengtao, the editor, once pointed out in the editorial gist of Kaiming Chinese Textbook that "the picture and the text in this book are organic cooperation; the picture is not only the description of the text, but also can expand children's imagination and cultivate children's aesthetic feeling" (Ye, 2014). Thus, it can be seen that the picture plays an irreplaceable role in writing. There are two kinds of picture reading practice in the fifth and sixth volumes of Kaiming Chinese Textbook, which are speaking and writing scripts. The author thinks that this kind of practice has three advantages, that is, improving students' ability to understand pictures, cultivating students' language sense, and increasing students' interest in learning Chinese. In terms of these pictures, there are many kinds, such as daily events and fables: for students who are hard to keep a high concentration, it may be more interesting to read pictures than boring words.

\section{Recommendations}

Through the summary of the characteristics of the practice after-class, we can summarize the enlightenment to the modern Chinese textbooks.

\section{Pay Attention to the Specific Situation of Font Diversification and Word Learning}

The practice of words in Kaiming Chinese Textbook focuses on the grasp of various fonts, that is, the practice of running script is carried out on the basis of mastering regular script. In the New Curriculum Standard "2019 Full Time Primary School Chinese Curriculum Standard", it is mentioned that students are required to master the writing of pencil, pen, and calligraphy. There is no clear requirement for mastering different fonts. Mr. Ye Shengtao wrote in changing the style of writing, "No matter in primary school, middle school, or university, the students who come out of the school can write correct words in one hand, educators and students work together, train carefully, set an example, and practice carefully. In such a situation, how difficult is it to make students write correctly?" (Ye, 2014). Therefore, the teaching of diversified fonts is inseparable from the practical efforts of teachers and students. Therefore, in order to improve the students' interest in practice and achieve the effect of practice, we should pay attention to the diversification and the specific situation of words learning.

\section{Promote the Writing Practice to be More Practical}

With the development of the times and the progress of science and technology, the telegraph and other styles in the period of the Republic of China are obviously no longer applicable. And because of the emergence of multimedia technology, more forms of style can appear. We believe that the purpose of students' mastery of various styles is no longer to deal with examinations, but to meet the needs of real life. Therefore, teachers 
should pay attention to teaching students all kinds of styles that meet the needs of the times. Although the writing style needs to be practical, just like Confucius's golden mean, teaching students to write cannot pay too much attention to the style form, especially in the context of exam oriented education, the teacher "tells the writing methods of various writing styles, such as 'the format of the envelope, the emphasis of expository text is to take examples to demonstrate...'. This kind of 'cramming teaching' mode has seriously hit students' interest in learning" (Sha, 2018). In addition, when students are required to master a certain style of writing, teachers need to consider students' reading situation, and the accumulation of reading volume will affect students' writing ability imperceptibly. For example, students are required to write expository text. Students should write on the basis of reading a considerable number of expository text. Mr. Ye Shengtao pointed out that "the article must be produced from the real life, and it is inevitable that it will be a failure to drag down the things that are not experienced in the real life" (Hu, 2007). In other words, how can a random composition fits reality?

\section{Improve the Activity Practice to Improve the Students' Brain and Hands-on Ability}

In modern primary school Chinese teaching, the purpose of activity practice is to grasp the basic knowledge of students and improve students' interest in Chinese learning. For example, teachers use multimedia to make sheep graze (new words) and other game activities to let students master the words, and read the content of the text to grasp the thoughts and feelings of the characters or characters in the text through student role-playing and other ways. However, the purpose of training hands-on and brain use ability is not as clear as in the Kaiming Chinese Textbook. Perhaps, modern Chinese textbooks can learn from the activities of after-class practice in Kaiming Chinese Textbooks, so as to improve students' brain and hands-on ability. The traditional classroom teaching is mainly taught by teachers, so it is hard for students to focus their attention. The arrangement of activities related to brain and hands-on activities in the after-class practice is not only conducive to maintaining students' high attention, but also to promoting the development of students' multiple intelligence.

\section{Add the Related Map Reading Exercise to Improve the Students' Cognitive Ability}

As for the picture, it embodies a kind of humanistic feeling in the Kaiming Chinese Textbook, which fully considers the cognitive ability of students at different stages, that is, with the development of students' age and cognitive ability, the performance of the picture changes. For example, the first volume of Kaiming Chinese Textbook is for the first grade students, and the pictures in the book will be more than the textbooks used by the senior students. In the same way, this also applies to the arrangement of reading pictures in after-class exercises. Therefore, the students' cognitive ability should be taken into account when drawing is used in the after-class practice of modern Chinese textbooks. Just like when Mr. Feng Zikai draws a picture, he will add appropriate words to the picture according to the difficulty of the text. In addition, in view of the wide popularity of Kaiming Chinese textbook, Mr. Feng Zikai's illustrations have also been widely studied and loved by the public. Perhaps in the process of the innovation of modern Chinese textbooks, Mr. Feng Zikai's works can also be properly added to the textbooks. If these exquisite illustrations only exist in textbooks in the period of the Republic of China, they cannot be known by modern children, which is indeed true unfortunately.

\section{Conclusions}

In the period of the Republic of China, there were many contents worthy of modern people's learning in art and education. In order to learn from the education in the period of the Republic of China, and to take into 
account, the increasing concern of modern education for the textbook of the Republic of China, we have carried out research on the textbook of the Republic of China (five or six volumes). Therefore, we sum up seven types of practice after-class in the Kaiming Chinese Textbook (Volumes 5 and 6): practice writing from the side and font, use words, words, and related words to make sentences, look at picture exercises, answer questions, organize ability questions, write letters and other questions, such as writing diary, imagination questions, etc. According to the above questions, four characteristics of after-class practice in Kaiming Chinese Textbook (Volumes 5 and 6) are obtained: word practice step-by-step, writing practice is practical, activity practice hand brain combination and picture reading practice are interesting. In order to improve the compilation of modern Chinese textbooks, we thinks that the enlightenment of after-class practice of Kaiming Chinese Textbooks for the compilation of modern Chinese textbooks is as follows: pay attention to the specific context of font diversification and word learning, writing practice is more practical, improve the activity practice to improve the students' brain and hands-on ability, and add relevant map reading exercises to improve the students' cognitive ability. All things are transformed into history under the influence of time, but classics will never be buried by time, only fewer and fewer people can appreciate them. Although the Chinese teaching materials in the period of the Republic of China are backward in time, the educational ideas, aims, and methods contained in them all indicate the shortcomings that need to be improved in modern education. If we do not want to let history sink, the most important way is to take its essence and discard its dross.

\section{References}

Chen, D. Q. (2012). Talk to Chen Danqing. Changsha: Hunan Literature and Art Press. (in Chinese)

Hu, X. F. (2007). Tao Xingzhi's education collection. Chengdu: Sichuan Education Press. (in Chinese)

Sha, M. M. (2018). The effective strategies of Chinese composition teaching in primary school. Curriculum Education Research, 10, 1. (in Chinese)

Shen, L. R. (2015). Children's standard: Arrangement of selected texts in primary school Chinese textbooks of the Republic of China. Educational Theory and Practice, 5, 48. (in Chinese)

Ye, S. T. (2014). On Ye Shengtao's Chinese education. Beijing: Education Science Press.

Yu, L. X. (2012). Research on Feng Zikai's aesthetic thought (p. 255). Beijing: Commercial Press. (in Chinese) 